\title{
KONTRIBUSI USAHA TRANSPORTASI "OJEK PERAHU” TERHADAP PENDAPATAN RUMAH TANGGA DI KELURAHAN SINDULANG KECAMATAN TUMINTING KOTA MANADO
}

\author{
Fernanda Grasela Ruauw'; Jardie A. Andaki²; Grace 0. Tambani² \\ 1)Mahasiswa Fakultas Perikanan dan IImu Kelautan Universitas Sam Ratulangi Manado \\ 2)Staff Pengajar Fakultas Perikanan dan IImu Kelautan Universitas Sam Ratulangi Manado \\ Koresponden email: fernandagrasela24@gmail.com
}

\begin{abstract}
Boats are the choice for transportation activities on the river. The condition of the Tondano River, specifically at the river mouth is suitable for boat crossings. The need to move from one side of the river to the other side of the river with various needs, raises remuneration for "mining" boats / ojek boats. Opinions generated from this remuneration contribute to family income.

The objectives of this study, namely: 1) identify the activities of "mining" boat / ojek boat transportation in the Tondano River Estuary of Manado City; and 2) determine the contribution of "mining" boat / ojek boat transportation activities in the Tondano River Estuary of Manado City to family income.

The subjects of this study were the people in Sindulang I and Sindulang II Subdistrict Tuminting Sub-District, Manado City who carried out the business of "mining" boats / ojek boats. While the objects in this study were household income in Sindulang I Village and Sindulang II Tuminting District, Manado City.

Analysis technique is an attempt to determine the answer to the question about the formula and the things obtained in a study. Data that has been entered and collected is analyzed to answer the research objectives. Data analysis techniques are adjusted to the research objectives. The data analysis techniques used in this study are as follows:

Analysis of the contribution of boat mining / ojek boat businesses to total household income is carried out by the percentage method. Contributions are contributions that can be given by something to other things. The data obtained were analyzed without statistical tests by calculating the amount of money obtained from a business activity "boat mining" / ojek boat and total household income multiplied by one hundred percent.

The results of the research and discussion can be concluded: 1) boat motorcycle taxi activities carried out in the form of ferry services and boat rental services for use as a means of fishing or fishing activities; 2) the contribution of boat motorcycle taxis to family income is $81.97 \%$, while the remaining $18.03 \%$ is contributed by other businesses outside the boat ojek business; 3) outpouring of work time causes the contribution of boat motorcycle taxis to be greater than the contribution of other businesses outside the boat ojek business.
\end{abstract}

Keywords: transportation, boat motorcycle taxi, activities, contributions

Abstrak

Perahu menjadi pilihan untuk aktivitas transportasi di sungai. Kondisi Sungai Tondano, khusus pada muara sungai cocok untuk penyeberangan menggunakan perahu. Kebutuhan untuk berpindah dari satu sisi sungai menuju sisi lain dari sungai dengan berbagai keperluan, menimbulkan balas jasa bagi perahu "tambangan" / ojek perahu. Pendapat yang dihasilkan dari balas jasa ini berkontribusi terhadap pendapatan keluarga.

Tujuan dari penelitian ini, yaitu : 1) mengidentifikasi aktivitas transportasi perahu "tambangan" / ojek perahu di Muara Sungai Tondano Kota Manado; dan 2) menentukan kontribusi aktivitas transportasi perahu "tambangan" / ojek perahu di Muara Sungai Tondano Kota Manado terhadap pendapatan keluarga.

Subjek penelitian ini adalah masyarakat di Kelurahan Sindulang I dan Sindulang II Kecamatan Tuminting Kota Manado yang menjalankan kegiatan usaha perahu "tambangan" / ojek perahu. Sedangkan objek dalam penelitian ini adalah pendapatan rumah tangga di Kelurahan Sindulang I dan Sindulang II Kecamatan Tuminting Kota Manado.

Teknik analisis merupakan suatu usaha untuk menentukan jawaban atas pertanyaan tentang rumusan dan hal-hal yang diperoleh dalam suatu penelitian. Data yang sudah masuk dan terkumpul dianalisis ubtuk menjawab tujuan penelitian. Teknik analisis data disesuaikan dengan tujuan penelitian. Adapun teknik analisis data yang digunakan dalam penelitian ini adalah sebagai berikut:

Analisis kontribusi usaha perahu "tambangan" / ojek perahu terhadap pendapatan total rumah tangga dilakukan dengan metode persentase. Kontribusi adalah sumbangan yang dapat diberikan oleh suatu hal terhadap hal lain. Data yang diperoleh dianalisis tanpa uji statistik dengan menghitung jumlah uang yang diperoleh dari suatu kegiatan usaha perahu "tambangan" / ojek perahu dan pendapatan total rumah tangga dikali seratus persen.

Hasil penelitian dan pembahasan dapat ditarik kesimpulan: 1) aktivitas ojek perahu dilakukan dalam bentuk jasa penyeberangan dan jasa sewa perahu untuk penggunaan sebagai sarana aktivitas pemancingan atau mencari ikan; 2) kontribusi usaha ojek perahu terhadap pendapatan keluarga sebesar $81,97 \%$, sedangkan sisanya $18,03 \%$ dikontribusi dari usaha lain di luar usaha ojek perahu; 3) curahan waktu kerja menyebabkan kontribusi pendapatan ojek perahu lebih besar dari kontribusi usaha lain di luar usaha ojek perahu.

Kata kunci : transportas, ojek perahu, aktivitas, kontribusi 


\section{PENDAHULUAN}

Aktivitas kehidupan masyarakat memerlukan transportasi guna berpindah dari satu ke tempat lainnya. Transportasi merupakan komponen utama dalam sistem hidup dan kehidupan, sistem pemerintahan, dan sistem kemasyarakatan. Kondisi sosial demografis wilayah memiliki pengaruh terhadap kinerja transportasi di wilayah tersebut. Tingkat kepadatan penduduk akan memiliki pengaruh signifikan terhadap kemampuan transportasi melayani kebutuhan masyarakat. Pada wilayah perkotaan, kecenderungan yang terjadi adalah meningkatnya jumlah penduduk yang tinggi karena tingkat kelahiran maupun urbanisasi. Tingkat urbanisasi berimplikasi pada semakin padatnya penduduk yang secara langsung maupun tidak langsung mengurangi daya saing dari transportasi wilayah (Susantoro dan Parikesit, 2004).

Kota Manado merupakan kota yang dialiri beberapa anak sungai." Sungai yang melewati kota Manado, yaitu : Sungai Tondano, Sungai Tikala, Sungai Sario, Sungai Bailang, dan Sungai Malalayang (Manado Dalam Angka, 2017). Sungai Tondano merupakan sungai terpanjang yang melewati Kota Manado, berhulu di Kota Tondano dan bermuara di Kelurahan Sindung dan Kawasan Pasar BERSEHATI Manado.

Keberadaan Sungai Tondano memiliki arti penting dalam kehidupan masyarakat kota Manado, selain sebagai sumber air untuk kebutuhan hidup sehari-hari, juga sebagai sarana transportasi. Sarana transportasi yang sudah lama berkembang di Kota Manado yaitu di muara, yaitu transportasi menggunakan perahu. Perahu "tambangan" / ojek perahu demikian orang umumnya mengistilahkan pada perahu yang digunakan untuk mengangkut penumpang dari satu sisi sungai ke sisi lainnya.

Aktivitas "tambangan" dilakukan di Kelurahan Sindulang I dan Sindulang II mengangkut penumpang yang hendak menuju Pasar BERSEHATI Manado. Perahu "tambangan" / ojek perahu ini sudah sejak tahun 1970 dan tetap bertahan hingga sekarang ini, walaupun tawaran jenis transportasi konvensional seperti oplet, ojek motor, Gojek, Grab dan transportasi online lainnya, namun perahu "tambangan" / ojek perahu masih mempunyai pelanggan.

Berdasarkan latar belakang ini, maka perlu dilakukan penelitian tentang keberadaan perahu "tambangan" / ojek perahu, terkait kontribusinya terhadap pendapatan keluarga. Hal ini menarik untuk dikaji, yaitu tidak mungkin suatu bentukan usaha dapat bertahan sekian lamanya jika tidak memiliki kontribusi terhadap pendapatan keluarga.

\section{Rumusan Masalah}

Perahu menjadi pilihan untuk aktivitas transportasi di sungai. Kondisi Sungai Tondano, khusus pada muara sungai cocok untuk penyeberangan menggunakan perahu. Kebutuhan untuk berpindah dari satu sisi sungai menuju sisi lain dari sungai dengan berbagai keperluan, menimbulkan balas jasa bagi perahu "tambangan" / ojek perahu. Pendapat yang dihasilkan dari balas jasa ini berkontribusi terhadap pendapatan keluarga. Berdasarkan hal ini maka dapat dirumuskan masalah, yaitu :

1. Bagaimana aktivitas transportasi perahu "tambangan" / ojek perahu di Muara Sungai Tondano Kota Manado? 
2. Bagaimana kontribusi aktivitas transportasi perahu "tambangan" / ojek perahu di Muara Sungai Tondano Kota Manado terhadap pendapatan keluarga?

\section{Tujuan Penelitian}

Tujuan dari penelitian ini, yaitu :

1. Mengidentifikasi aktivitas transportasi perahu "tambangan" / ojek perahu di Muara Sungai Tondano Kota Manado

2. Menentukan kontribusi aktivitas transportasi perahu "tambangan" I ojek perahu di Muara Sungai Tondano Kota Manado terhadap pendapatan keluarga

\section{METODE PENELITIAN}

Desain penelitian ini adalah penelitian survei. Menurut Singarimbun dan Efendy (2008) informasi dalam penelitian survei dikumpulkan dari responden dengan menggunakan kuesioner. Penelitian survei adalah penelitian yang mengambil sampel dari satu populasi dan menggunakan kuesioner sebagai alat pengumpul data yang pokok. Dalam penelitian ini dilakukan survei mengenai besarnya kontribusi pendapatan usaha perahu "tambangan" ojek perahu terhadap pendapatan rumah tangga di Kelurahan Sindulang I dan Sindulang II Kecamatan Tuminting Kota Manado.

Subjek penelitian ini adalah masyarakat di Kelurahan Sindulang I dan Sindulang II Kecamatan Tuminting Kota Manado yang menjalankan kegiatan usaha perahu "tambangan" I ojek perahu. Sedangkan objek dalam penelitian ini adalah pendapatan rumah tangga di Kelurahan Sindulang I dan Sindulang II Kecamatan Tuminting Kota Manado.
Teknik analisis merupakan suatu usaha untuk menentukan jawaban atas pertanyaan tentang rumusan dan hal-hal yang diperoleh dalam suatu penelitian. Data yang sudah masuk dan terkumpul dianalisis untuk menjawab tujuan penelitian. Teknik analisis data disesuaikan dengan tujuan penelitian. Adapun teknik analisis data yang digunakan dalam penelitian ini adalah sebagai berikut:

Analisis ini digunakan untuk mengetahui kontribusi usaha perahu "tambangan" / ojek perahu terhadap pendapatan total rumah tangga dalam satuan persen. Kontribusi adalah sumbangan yang dapat diberikan oleh suatu hal terhadap hal lain. Data yang diperoleh dianalisis tanpa uji statistik dengan menghitung jumlah uang yang diperoleh dari suatu kegiatan usaha perahu "tambangan" / ojek perahu dan pendapatan total rumah tangga dikali seratus persen.

Untuk mengetahui kontribusi usaha perahu "tambangan" / ojek perahu terhadap pendapatan total rumah tangga digunakan rumus persentase sebagai berikut :

Kontribusi $(\%)=\frac{\text { Pendopatan Usaha Perahu "Tanbangan" }}{\text { Pendapatan Total } \text { Rumah Tangga }} \times 100 \%$

Analisis kualitatif dengan cara menginterpretasikan hasil analisis dengan kata-kata dan narasi terkait perumusan masalah dan tujuan penelitian untuk pengambilan keputusan.

\section{HASIL DAN PEMBAHASAN}

\section{Aktivitas Transportasi Ojek Perahu}

Aktivitas trasportasi ojek perahu dilakukan pada muara Sungai Tondano di Kelurahan Sindulang Kecamatan Tuminting Kota Manado. Aktivitas ojek perahu dilakukan sejak subuh (05.00 - 
10.00), merupakan waktu paling ramai penumpang perahu "tambangan", saat mana pasar Bersehati di Kota Manado memulai aktivitas jual beli (Andaki, et.al., 2012). Selepas pukul 10.00 penumpang akan semakin berkurang seiring dengan berkurangnya aktivitas jual beli di pasar. Penumpang akan kembali lagi ramai pada pukul 16.00 - 18.00, karena pasar di sini selalu ada sepanjang hari. Pukul 18.00 ialah waktu berakhirnya kegiatan perahu "tambangan", walaupun ada saja yang mencoba peruntungan dari penumpang yang pulang malam (biasanya para penjual di pasar Bersehati).

Selain perahu digunakan sebagai ojek, perahu juga digunakan untuk aktivitas mencari ikan. Dilaporkan oleh Andaki et.al., (2012), bahwa perahu "tambangan" seringkali digunakan sebagai perahu nelayan melalui sistem sewa kepada pemilik perahu. Harga sewa untuk sekarang ini (2018) sudah mencapai Rp. 75.000 (mulai jam 09.00 20.00).

\section{Pendapatan "Ojek Perahu" dan Pendapatan Lain}

Pendapatan ojek perahu didapat dari aktivitas mengantar penumpang menyeberangi sungai. Titik penyeberangan dari Kelurahan Sindulang I dan Sindulang II menuju Pasar Bersehati Manado. Demikian pula sebalikya.

Jasa mengantar penumpang diharga Rp. 2.000 per orang untuk satu kali penyeberangan. Pendapatan per hari kemudian dirata-ratakan untuk 7 hari kerja per minggu dan 4 minggu per bulan.

Pendapatan lainnya merupakan pendapatan yang pekerjaan di luar usaha ojek perahu, yaitu pendapatan dari ibu rumah tangga dan pendapatan dari responden di luar ojek perahu, misalnya sebagai buruh bangunan, tukang ojek motor dan buruh toko, serta pekerjaan lainnya. Hasil penelitian terhadap pendapatan responden ojek perahu dan pendapatan lainnya, dapat dilihat pada tabel berikut.

Tabel. 1. Sumber Pendapatan Responden Ojek Perahu dan Pendapatan Lainnya

\begin{tabular}{|c|c|c|}
\hline \multirow{2}{*}{ Responden } & \multicolumn{2}{|c|}{ Jenis Pendapatan (Rp. Per bulan) } \\
\hline & Ojek Perahu & Lainnya \\
\hline 1 & 1.600 .000 & 240.000 \\
\hline 2 & 3.600 .000 & 0 \\
\hline 3 & 1.800 .000 & 0 \\
\hline 4 & 3.000 .000 & 0 \\
\hline 5 & 2.160 .000 & 0 \\
\hline 6 & 2.080 .000 & 750.000 \\
\hline 7 & 1.440 .000 & 360.000 \\
\hline 8 & 2.600 .000 & 0 \\
\hline 9 & 2.600 .000 & 660.000 \\
\hline & 2.520 .000 & 1.500 .000 \\
\hline 11 & 2.880 .000 & 0 \\
\hline 12 & 2.400 .000 & 2.800 .000 \\
\hline Jumlah & 28.680 .000 & 6.310 .000 \\
\hline Rata-rata & 2.390 .000 & 525.833 \\
\hline
\end{tabular}

Sumber: Data Primer (2018)

Data ini menunjukkan rata pendapatan ojek perahu per bulan berkisar Rp. 2.390.000. Sedangkan pendapatan di luar usaha ojek perahu rata-rata per bulan $\mathrm{Rp}$. 525.833. Jadi terlihat bahwa jumlah pendapatan ratarata per dari usaha ojek perahu lebih besar dari rata-rata pendapatan per bulan dari usaha di luar ojek perahu.

Kondisi ini disebabkan oleh curahan waktu tenaga kerja sebagian besar pada aktivitas ojek perahu. Aktivitas di luar usaha ojek perahu hanya dilakukan sebagai sampingan saja, ketika sungai tidak layak dan berbahaya untuk diseberangi. Kondisi bahaya dimaksud ialah arus yang kuat, angin dan hujan deras. 
Curahan waktu kerja yang banyak inilah yang menyebabkan pendapatan ojek perahu jauh melebih pendapatan dari usaha di luar ojek perahu. Hal ini sama dengan pernyataan Pass (1997), bahwa kondisi seseorang dapat diukur dengan menggunakan konsep pendapatan yang menunjukan jumlah seluruh uang yang diterima oleh seorang selama jangka waktu tertentu atau curahan waktu kerja.

\section{Kontribusi Pendapatan "Ójek Perahu"} Kontribusi pendapatan ojek perahu merupakan perbandingan antara

\begin{tabular}{|c|c|c|c|c|}
\hline \multirow{2}{*}{ Responden } & \multicolumn{2}{|c|}{ Jenis Pendapatan (Rp.) } & \multirow{2}{*}{$\begin{array}{l}\text { Total Pendapatan } \\
\text { (Rp.) }\end{array}$} & \multirow{2}{*}{ sstribusi (\%) } \\
\hline & Ojek Perahu & Lainnya & & \\
\hline 1 & 1.600 .000 & 240.000 & 1.840 .000 & 86,96 \\
\hline 2 & 3.600 .000 & 0 & 3.600 .000 & 100,00 \\
\hline 3 & 1.800 .000 & 0 & 1.800 .000 & 100,00 \\
\hline 4 & 3.000 .000 & 0 & 3.000 .000 & 100,00 \\
\hline 5 & 2.160 .000 & 0 & 2.160 .000 & 100,00 \\
\hline 6 & 2.080 .000 & 750.000 & 2.830 .000 & 73,50 \\
\hline 7 & 1.440 .000 & 360.000 & 1.800 .000 & 80,00 \\
\hline 8 & 2.600 .000 & 100 & 2.600 .000 & 100,00 \\
\hline 9 & 2.600 .000 & 660.000 & 3.260 .000 & 79,75 \\
\hline 10 & 2.520 .000 & 1.500 .000 & 4.020 .000 & 62,69 \\
\hline 11 & 2.880 .000 & 0 & 2.880 .000 & 100,00 \\
\hline 12 & 2.400 .000 & 2.800 .000 & 5.200 .000 & 46,15 \\
\hline Jumlah & 28.680 .000 & 6.310 .000 & 34.990 .000 & \multirow{2}{*}{81,97} \\
\hline Rata-rata & 2.390 .000 & 525.833 & 2.915 .833 & \\
\hline
\end{tabular}

Sumber: Data Primer (2018)

Hasil analisis kontribusi usaha ojek perahu didapat hasil $81,97 \%$, sedangkan 18,03\% dikontribusi oleh pendapatan dari usaha di luar ojek perahu. Besarnya kontribusi pendapatan ojek perahu tidak lepas dari jumlah curahan waktu kerja.

Curahan waktu kerja dari responden sangat besar pada usaha ojek perahu. Alokasi waktu untuk ojek perahu besar karena dilakukan sampai 7 kali per minggu, pada durasi waktu aktivitas jam 05.00 - 10.00 dan jam pendapatan dari aktivitas ojek perahu terhadap total pendapatan keluarga. Kontribusi dinyatakan dalam persentase guna mendeskripsikan secara kuantitatif kontribusi usaha responden ojek perahu terhadap pendapatan keluarga.

Hasil penelitian terhadap kontribusi pendapatan responden ojek perahu terhadap pendapatan keluarga, dapat dilihat pada tabel berikut.

Tabel 2. Kontribusi Pendapatan Ojek Perahu Terhadap Pendapatan Keluarga 
tidak memungkinkan untuk melakukan jasa penyeberangan dengan perahu di Sungai Tondano Kota Manado.

\section{KESIMPULAN DAN SARAN \\ Kesimpulan}

Hasil penelitian dan pembahasan dapat ditarik kesimpulan:

Aktivitas ojek perahu dilakukan dalam bentuk jasa penyeberangan dan jasa sewa perahu untuk penggunaan sebagai sarana aktivitas pemancingan atau mencari ikan

Kontribusi usaha ojek perahu terhadap pendapatan keluarga sebesar $81,97 \%$, sedangkan sisanya $18,03 \%$ dikontribusi dari usaha lain di luar usaha ojek perahu Curahan waktu kerja menyebabkan kontribusi pendapatan ojek perahu lebih besar dari kontribusi usaha lain di luar usaha ojek perahu.

\section{Saran}

Saran yang dapat diberikan terkait hasil penelitian ini, ialah: perlu adanya penelitian lanjutan untuk mengkaji eksistensi terkait kondisi sosial ekonomi pekerja ojek perahu.

\section{DAFTAR PUSTAKA}

Andaki, J.A., Mamuaya, G.E., and Lengkey, N. 2012. Adaptation of Fishing Communities In Coastal Reclamation Areas On Manado City. Lucrari Stiintifice Medicina Veterinara. IASI. Romania. ISSN 1454-7406 Vol 55 (NR. 3-4)
Badan Pusat Statistik Kota Manado, 2017. Kota Manado Dalam Angka. BPS Kota Manado.

Badan Pusat Statistik. 1998. Indikator Kesejahteraan Rumah Tangga 1998. Jakarta: BPS.

Bambang, S., 1994, Analisis Laporan Keuangan. Jakarta: LP3ES.

Miro, F., 2005. Perencanaan Transportasi. Jakarta: Erlangga.

Moleong L.J., 2006. Metodologi Penelitian Kuantitatif. Bandung: PT Remaja Rosdakarya Offiset.

Morlok, E.K., 1988. Pengantar Teknik dan Perencanaan Transportasi (Editor: Yani Sianipar). Jakarta: Erlangga.

Mubyarto, 1998. Pembangunan dan Pemberdayaan Masyarakat. Yogyakarta: Pustaka Pelajar.

Nasution, M.N., 2004. Manajemen Transportasi (Edisi Kedua). Jakarta: Ghalia Indonesia.

Pass, C., 1997. Teori Makro Ekonomi. Jakarta.

Salim, H.A.A., 2002. Manajemen Transportasi. Jakarta: Raja Grafindo.

Sari, R.P., 2008. Pergeseran Pergerakan Angkutan Di Sungai Martapura Kota Banjarmasin. Semarang (Tesis): Universitas Diponegoro.

Sastika, A., 2017. Analisis Tingkat Pelayanan Perahu Ketek Sebagai Angkutan Wisata di Sungai Musi Kota Palembang. Tesis. Program Pascasarjana Magister Teknik. Fakultas Teknik. Universitas Lampung. Bandar Lampung.

Singarimbun, M dan Effendi, S., 2008. Metode Penelitian Survei, Jakarta: LP3ES.

Soekartawi, 1995. Analisis Usaha Tani. Jakarta:UIPress.

Sugiyono, 2011. Metode Penelitian kuantitatif kualitatif dan R\&D. Bandung: Alfabeta. 